\title{
An unusual foreign object mimicking an odontoma in a patient with cleft alveolus: a case report
}

\author{
Nadeena Sri Swarnagupta Jayasuriya ${ }^{1 *}$, Pallege Ralalage Chandana Lakmal Karunathilaka ${ }^{2}$ \\ and Parakrama Wijekoon ${ }^{1}$
}

\begin{abstract}
Background: The habit of inserting foreign objects into body cavities is seen in children and in adults with intellectual disability. Usually, the foreign objects cause chronic inflammation and local tissue destruction, which give rise to symptoms. Diagnosis at an asymptomatic stage is uncommon when the history is not suggestive. We describe a rare case where a foreign object was misdiagnosed as an odontoma in a patient with an alveolar cleft.

Case presentation: A radiopaque round mass was noted on the radiograph of a 12-year-old Sinhalese boy who was awaiting an alveolar bone graft. Apart from problems related to the alveolar cleft and mild halitosis, he was otherwise healthy. This was suspected to be an odontoma in the cleft region. During alveolar bone graft surgery, a button battery was recovered that was later confirmed as having been self-inserted by the child. Alveolar bone graft surgery was delayed because of local chronic inflammation due to the foreign object. Three months later, complete healing of the site was noted when reexplored for alveolar bone grafting.

Conclusions: It is important to include foreign objects in the radiological differential diagnosis in asymptomatic children. Furthermore, cone beam computed tomography should be considered in suspected cases. Early removal with thorough debridement causes minimal tissue destruction.
\end{abstract}

Keywords: Foreign body, Button battery, Cleft alveolus, Self-inflicted, Case report

\section{Background}

Foreign bodies cause serious harm due to chronic irritation and infection, in addition to the risk of aspiration by small children. Foreign objects (FOs) recovered from the head and neck region include fish bones, pieces of gauze, coins, buttons, beads, small pieces of toys, ectopic teeth, pieces of steel wire, nutshells, pieces of wood, artificial fingernails, and "opiomas" [1-5]. The most common site for impacted FOs is the nasal cavity. Other significant sites reported include the oral cavity (base of the tongue, hard palate), tonsils, piriform fossae, hypopharynx, cervical esophagus, and nasopharynx $[1,6]$.

Long-standing FOs in the head and neck are usually diagnosed after they give rise to symptoms [3, 4]. At the

\footnotetext{
*Correspondence: nadeenaj@pdn.ac.lk

'Department of Oral and Maxillofacial Surgery, Faculty of Dental Sciences,

University of Peradeniya, Peradeniya, Sri Lanka

Full list of author information is available at the end of the article
}

presymptomatic stage, an unsuspected FO is rarely confused with a normal structure or in the differential diagnosis involving radiological investigations. We report a case of an asymptomatic FO in an unrepaired alveolar cleft that was misdiagnosed as an odontoma on the basis of a plain radiograph.

\section{Case presentation}

A 12-year-old Sinhalese boy from Kandy District, Sri Lanka, with a unilateral alveolar cleft was seen at a routine appointment in the cleft joint clinic of our institution. Apart from mild halitosis complained of by his mother, the boy was asymptomatic and was awaiting alveolar bone graft surgery. His halitosis was not clinically significant, and no accompanying discharges from his nostrils or oral cleft were noted. The palatal mucosa over the suspected lesion was noted to be slightly paler than the other regions. On palpation, the lesion was 
firm, nontender, and immobile. An upper standard occlusal radiograph through the alveolar cleft showed a well-demarcated, circumscribed, radiopaque mass in the palatal bone associated with the cleft (Fig. 1).

An odontoma or an ectopic tooth were the most likely diagnoses, considering the radiological appearance, which was of similar intensity to enamel; the appearance of a follicle-like structure; and the site of the lesion. To determine the exact location and the dimensions, cone beam computed tomography (CBCT) was suggested. The parents of the child did not consent to additional radiographic imaging, owing to fear of multiple radiation exposures and for financial reasons. Therefore, surgical removal with the patient under general anesthesia at the time of the alveolar bone graft surgery was planned.

At the time of the surgery, a dark-colored, circumscribed lesion was noted to be impacted in the posterior part of the alveolar cleft. It was seen tightly fixed to the palatal mucosa due to fibrosis. After removal, cleaning, and examination of the lesion, a small button cell-type battery was identified (Figs. 2 and 3). A certain degree of fibrosis, bone resorption, and mucosal discontinuity was noted surrounding the FO; thus, alveolar bone graft surgery was considered unsuitable and postponed. Corrosion or leak of chemicals from the battery was not noted. Even after retrieval, the child denied inserting the object into his nose or mouth. Because he had no previous history, psychiatric referral was not considered.

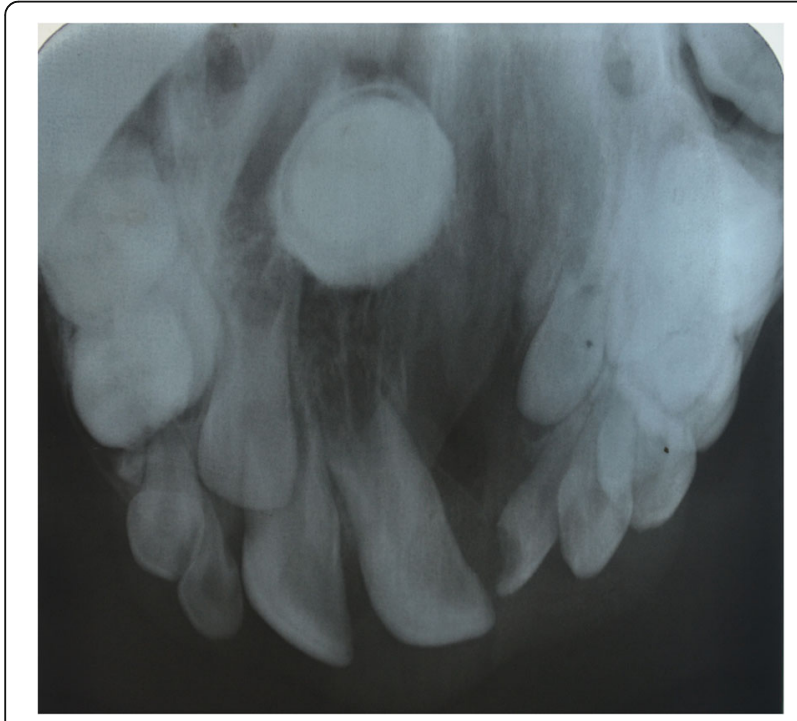

Fig. 1 Upper standard occlusal radiograph showing a well-defined, circumscribed, radiopaque lesion in the midposterior palate. A rim of radiolucency mimicking a dental follicle was noted at the posterior margin

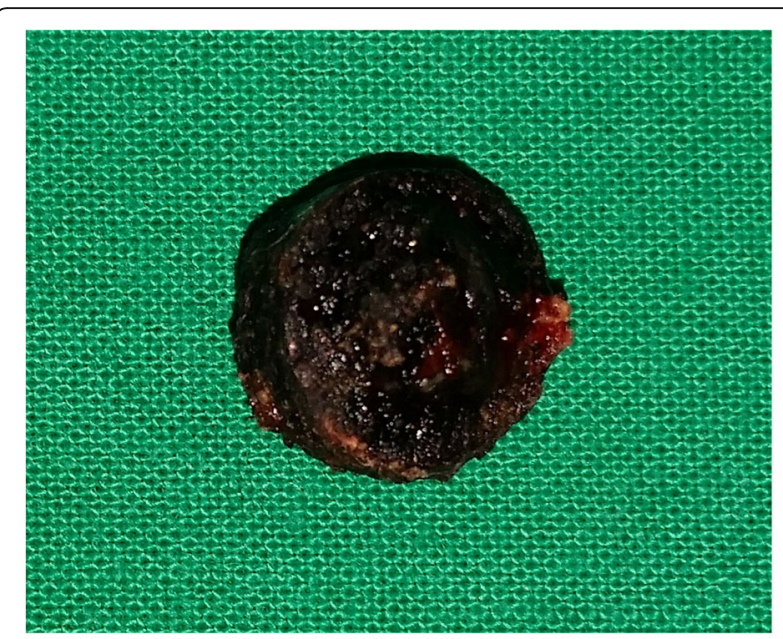

Fig. 2 The lesion soon after extraction from the palate

\section{Discussion}

The aerodigestive tract is a common site into which exogenous FOs are inserted. The child's inquisitive nature and impulsive behavior may have contributed to such behavior, and due to fear, the child may have abstained from revealing this to adults [4].

The clinical presentation changed due to the object's location, composition, and depth of penetration [5]. However, the encounter of an FO at an asymptomatic stage causes a dilemma in diagnosis, especially when previous history of FO insertion is absent.

FO impactions clinically misdiagnosed as palatal neoplasms and salivary gland tumors in the oral cavity are reported in the literature $[4,6]$. To the best of our knowledge, we report the first case in which an FO mimicked an odontoma during radiographic evaluation.

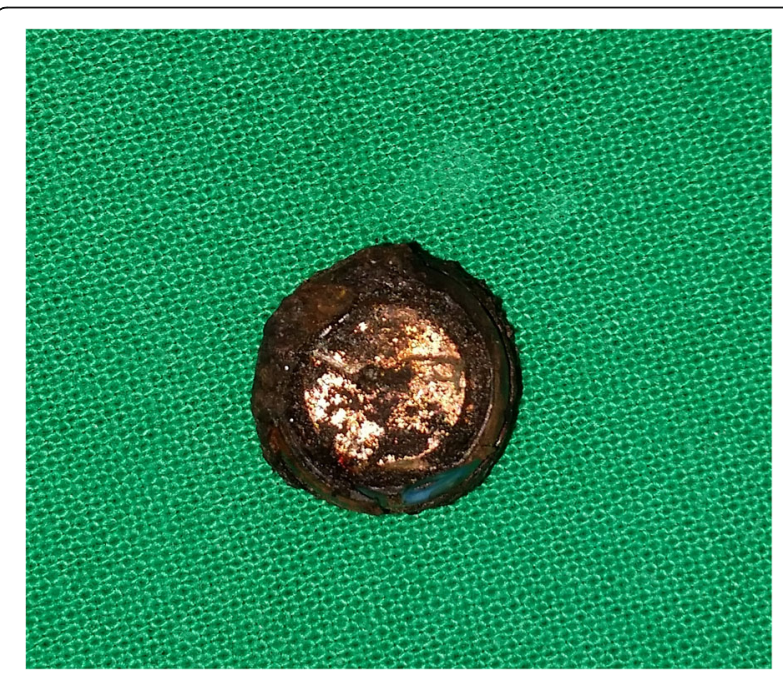

Fig. 3 A cell-type button battery was seen after the lesion was cleaned 
The possible harmful effects of an impacted FO are aspiration, ingestion, local tissue irritation, and penetration into the body's tissues. Subsequently, corrosive and toxic chemicals such as mercury, silver, alkaline manganese, and lithium of a cell-type battery can leak, causing lethal hazards to the patient [5]. The local tissue irritation may vary with the battery's charge status [2]. Fortunately, in our patient, only mild tissue destruction due to chronic inflammation was noted. On subsequent reexploration for alveolar bone graft surgery, no significant tissue destruction was noted.

We feel that the conventional radiograph was a limitation leading to misdiagnosis. Due to finances involved, $\mathrm{CBCT}$ is not performed as a first-line radiological investigation in most cases in our practice.

\section{Conclusions}

FO impaction in the head and neck area can happen among children. It is important to include FO impaction in the differential diagnosis because it can mimic different entities/pathologies in radiographic evaluation. In addition, advance imaging such as $\mathrm{CBCT}$ in suspected cases should be performed for further clarification.

\section{Abbreviations}

CBCT: Cone beam computed tomography; FO: Foreign object

\begin{abstract}
Acknowledgements
The authors are thankful to Mahes Salgado, head of the English Language Teaching Unit, University of Peradeniya, for editorial help and to Dr. Buddhika Dassanayake, registrar in the Oral and Maxillofacial Surgery Unit, Dental Hospital (Teaching), Peradeniya, Sri Lanka, for assisting in the surgical management of this child.
\end{abstract}

\section{Funding}

No funding was obtained for this manuscript.

Availability of data and materials

The photos used in this case report are published within the report.

\section{Authors' contributions}

NSSJ was involved in drafting, editing, and submitting the manuscript to the journal. PRCLK was involved in drafting parts of the manuscript. PW was involved in patient management and final editing of the manuscript.

All authors read and approved the final manuscript.

\section{Ethics approval and consent to participate}

All investigations and treatment were performed in accordance with ethical standards. No separate ethics approval was needed.

\section{Consent for publication}

Written informed consent was obtained from the patient's legal guardians for publication of this case report and any accompanying images. A copy of the written consent is available for review by the Editor-in-Chief of this journal.

\section{Competing interests}

The authors declare that they have no competing interests.

\section{Publisher's Note}

Springer Nature remains neutral with regard to jurisdictional claims in published maps and institutional affiliations.

\section{Author details}

Department of Oral and Maxillofacial Surgery, Faculty of Dental Sciences, University of Peradeniya, Peradeniya, Sri Lanka. ${ }^{2}$ Oral and Maxillofacial

Surgery Unit, Dental Hospital (Teaching), Peradeniya, Sri Lanka.

Received: 26 May 2017 Accepted: 20 August 2017

Published online: 26 September 2017

\section{References}

1. Al-Sebeih K, Valvoda M, Sobeih A, Al-Sihan M. Perforating and migrating pharyngoesophageal foreign bodies: a series of 5 patients. Ear Nose Throat J. 2006;85(9):600-3.

2. David TJ, Ferguson AP. Management of children who have swallowed button batteries. Arch Dis Child. 1986;61(4):321-2.

3. Ghanbarl H, Farhadl M, Daneshl A. Report of an unusual cause of rhinolithiasis: an 'opioma'. Ear Nose Throat J. 2007;86(1):48-9.

4. Hussain K, Brown AJ, Chavda D. Case report: foreign body in the palate of an infant. Br Dent J. 2008;205(1):23-5.

5. Ozer C, Ozer F, Sener M, Yavuz H. A forgotten gauze pack in the nasopharynx: an unfortunate complication of adenotonsillectomy. Am J Otolaryngol. 2007;28(3):191-3.

6. Tewari N, Singh N, Singh S, Agarwal N, Gupta NK. Corpus alienum on hard palate - an unusual "misdiagnosis" of foreign body: a case report. Int J Pediatr Otorhinolaryngol. 2015;79(12):2463-5.
Submit your next manuscript to BioMed Central and we will help you at every step:

- We accept pre-submission inquiries

- Our selector tool helps you to find the most relevant journal

- We provide round the clock customer support

- Convenient online submission

- Thorough peer review

- Inclusion in PubMed and all major indexing services

- Maximum visibility for your research

Submit your manuscript at www.biomedcentral.com/submit
C Biomed Central 